\title{
Immunohistochemical Detection of Fibroblast Growth Factor Receptors in Normal Endocrine Cells and Related Tumors of the Digestive System
}

\author{
Stefano La Rosa, M.D., *Silvia Uccella, M.D., *Silvia Erba, B.Sc, \\ *Carlo Capella, M.D., and *Fausto Sessa, M.D.
}

\begin{abstract}
Endocrine tumors (ETs) of the digestive system produce several growth factors including acidic and basic fibroblast growth factors (aFGF and bFGF, respectively), which are thought to be involved in the growth of tumor cells and in the proliferation of tumor stromal cells. Their actions depend on binding to four specific receptors-FGFR1, FGFR2, FGFR3, and FGFR4whose distribution in normal endocrine cells and related tumors of the gastroenteropancreatic (GEP) system has previously been examined. Formalin-fixed, paraffin-embedded normal tissues and 60 well-characterized GEP endocrine tumors were immunostained using specific antibodies directed against various GEP hormones, aFGF, FGFR1, FGFR2, FGFR3, and FGFR4. Acidic FGF immunoreactivity (IR) was found in gut EC cells; FGFR 1 immunoreactivity in rare duodenal endocrine cells and in pancreatic A cells; FGFR2 immunoreactivity in gastric and duodenal G cells, pancreatic B cells, and rectal EC cells; FGFR3 immunoreactivity in duodenal G cells; and FGFR4 immunoreactivity in rectal $\mathrm{L}$ cells and in pancreatic $\mathrm{B}$, $\mathrm{PP}$, and A cells. Immunoreactivity for at least one of the four FGFRs was found in all tumors, independently of FGFR expression in the putative cell of origin. EC cell tumors, which were all positive for $\mathrm{aFGF}$, were found to express at least three different FGFRs. FGFRs also were localized in the stromal cells of all the tumors examined. The tumor stroma was more abundant in EC cell tumors than in other types of neoplasms. The results suggest that aFGF-FGFR interaction may be involved in the modulation of normal endocrine cell functions and in the regulation of tumor growth and stromal proliferation of EC cell carcinoids.
\end{abstract}

Key Words: Acidic fibroblast growth factor-Endocrine tumors-Fibroblast growth factor receptor-Immunohistochemistry.

Applied Immunohistochemistry \& Molecular Morphology 9(4): $319-328,2001$.

Gastroenteropancreatic (GEP) endocrine tumors (ETs) show several characteristic stromal patterns, including desmoplastic reaction around tumor cells, proliferation

Manuscript received August 29, 2000; accepted January 23, 2001. From the Department of Pathology, Ospedale di Circolo, and *Department of Clinical and Biological Sciences, University of Insubria, Varese, Italy.

This study was supported by a grant from the University of Insubria, Varese, Italy.

Address correspondence and reprint requests to Prof. Carlo Capella, Servizio di Anatomia Patologica, Ospedale di Circolo, Viale Borri, 57, 1-21100 Varese, Italy. E-mail: Carlo.Capella@ospedale.varese.it of smooth muscle cells within the tumor stroma, and nerve and muscular hypertrophy of the wall infiltrated by the neoplasm. Moreover, in the case of EC cell carcinoids, fibrosis of the peritoneal and retroperitoneal tissue is observed, often in association with obliterative elastic sclerosis of mesenteric blood vessels and sometimes with fibroelastosis of the inside surfaces of the right cardiac chambers and valvular leaflets (1-3).

The tumorigenesis and growth of GEP ETs and mechanisms involved in the pathogenesis of the above described stromal lesions have not been fully clarified. In recent years, the role of various growth factors and their receptors in the pathobiology of GEP ETs has been investigated (4-17). Among various growth factors, it has been suggested that acidic and basic fibroblast growth factors (aFGF and bFGF, respectively) are possibly involved in the pathogenesis of fibromuscular proliferation within the tumor stroma $(14,15,18)$. Moreover, de novo expression of FGFR4 in neoplastic cells seems to be implicated in the tumorigenesis of EC cell tumors (15).

Acidic FGF and bFGF are the best characterized members of the fibroblast growth factor family, which includes at least 20 structurally related proteins (19-31). Acidic FGF and bFGF show approximately 55\% of structural homology and are involved in a wide array of biologic functions and pathologic mechanisms including fetal development, tissue repair, angiogenesis, proliferation of epithelial- and mesoderm-derived cells (fibroblasts and smooth muscle cells), and tumor development and growth (32).

The biologic functions of these two growth factors depend on binding to highly specific cell surface receptors. The family of fibroblast growth receptors (FGFRs) includes at least four peptides-FGFR1, FGFR2, FGFR3, and FGFR4. Their structure consists of an extracellular ligand-binding domain, an intracellular tyrosine-kinase domain, and a transmembrane domain (33). Acidic FGF and bFGF can bind to all of these receptors, but with different affinity. The expression of FGFRs in normal endocrine cells and related tumors of the gut and pancreas has been poorly investigated $(8,12$, $15,16)$, and, to the best of the authors' knowledge, systematic studies on their specific distribution in the cells 
of GEP endocrine system have not been reported previously.

The current study was designed to investigate immunohistochemically the specific cell distribution of FGFRs in ETs and related normal cells of the GEP endocrine system.

\section{MATERIALS AND METHODS}

Sixty normal tissues of the gut and pancreas ( 8 from subjects without neoplastic lesions and 52 from histologically normal peritumoral tissues of patients with the endocrine neoplasms investigated in the current study) and 60 immunophenotypically well-characterized (Table 1) GEP ETs were collected at surgery, fixed in buffered formalin (formaldehyde 4\% [wt:vol] and acetate buffer $0.005 \mathrm{~mol} / \mathrm{L}, \mathrm{pH} 7.4$ ) for 24 hours, and then embedded in paraffin. As reported in Table 2, the functional cell types of the gut and pancreas have been identified and characterized based on their hormonal expression (34). Sections were stained with hematoxylin and eosin and Grimelius' silver impregnation for histopathologic evaluation and Van Gieson stain for the evaluation of tumor fibrous stroma. According to previously published criteria (15), the amount of fibrous stroma was scored as scant $(1+)$, moderate $(2+)$, or abundant $(3+)$, whereas the smooth muscle cell component of the tumor stroma, evaluated immunohistochemically using anti- $\alpha$-smooth muscle specific actin antibody, was scored as scant (1+) or abundant $(2+)$. The amount of both fibrous and muscular stroma was assessed for every case, and the mean values for total, fibrous, and muscular stroma were indicated for the various tumor groups.

For immunohistochemical stains, $3-\mu \mathrm{m}$-thick sections were mounted on poly-L-lysine-coated slides and then deparaffinized and hydrated through graded alcohols to water. Endogenous peroxidase activity was inhibited treating sections with $3 \%$ hydrogen peroxide for 10 minutes. Primary antibody incubations (Table 3 ) were performed at $4^{\circ} \mathrm{C}$ for 18 to 20 hours, followed by the avidinbiotin-peroxidase complex $(\mathrm{ABC})$ method according to $\mathrm{Hsu}$ et al. (35). Immunoreactions were developed with $0.03 \% 3,3^{\prime}$-diaminobenzidine tetrahydrochloride and then sections were counterstained with Harris' hematoxylin. Colocalization studies were performed using serial reverse face sections, semithin-plastic sections, and double-label immunohistochemical techniques according to Mason and Sammons (36) and to Lan et al. (37). Sections incubated with antibodies directed against Nterminal glucagon-glicentin, glucagon, and somatostatin were pretreated with $0.003 \%$ subtilisin (Sigma, P478; Sigma, St. Louis, MO; protease type XXVII or Nagarse protease) in $0.005 \mathrm{~mol} / \mathrm{L}$ Tris-buffered saline, $\mathrm{pH} 7.4$ for 10 minutes at room temperature. Sections immunostained for FGFRl and FGFR3 were pretreated with
$0.05 \%$ trypsin (Sigma) in $0.05 \mathrm{~mol} / \mathrm{L}$ Tris-buffered saline, $\mathrm{pH} 7.4$, for 20 minutes at $37^{\circ} \mathrm{C}$. Finally, sections stained for aFGF, FGFR2, and FGFR4 were pretreated with $0.01 \mathrm{~mol} / \mathrm{L}$ citrate buffer, $\mathrm{pH} 6$, for 10 minutes in a microwave oven at $650 \mathrm{~W}$. Specificity controls consisted of absorption of antibodies and antisera with 10 to 20 $\mathrm{nM} / \mathrm{mL}$ of their related antigens, omission of the first layer, and use of control tissues with or without the pertinent antigen.

Results have been statistically evaluated using the Fisher exact test and the Wilcoxon test. Two variables were considered significantly different when $P<0.05$.

\section{RESULTS}

\section{Normal Tissues}

Acidic FGF immunoreactivity (IR) was observed in the cytoplasm of several endocrine cells dispersed along the entire gastrointestinal tract (Table 4). Acidic FGF immunoreactive cells were rare in the gastric mucosa, whereas they were numerous in the small bowel, appendix, colon, and rectum. Colocalization studies showed that aFGF-positive endocrine cells were a subgroup (approximately $30 \%$ ) of serotonin-producing enterochromaffin (EC)-cells. Acidic FGF immunoreactivity was absent in the other functional types of endocrine cells, including those of the pancreatic islets.

FGFR1-positive endocrine cells were rare in the ampullary region of the duodenum, whereas they were not identified in the stomach and along the intestinal tract, including the jejunum, ileum, appendix, colon, and rectum. However, several endocrine cells immunoreactive for FGFR 1 were observed in the pancreas and doublelabel immunostains demonstrated that FGFR1 immunoreactive cells were represented by a subgroup of glucagon-producing A cells.

FGFR2 was localized in several gastrin-producing G cells of the pyloric and duodenal mucosa and in a subpopulation of serotonin-producing EC cells of the rectal mucosa. However, FGFR2-IR was not detected in any endocrine cell of the ileal, appendiceal, and right colon mucosa. In the pancreatic islets, double label immunostains demonstrated that insulin-producing $B$ cells were strongly FGFR2-immunoreactive, whereas A, D, and PP cells were FGFR2-negative (Fig. 1).

FGFR3 IR was found in some $\mathrm{G}$ cells of the pyloric and duodenal mucosa (Fig. 2) and in rare pancreatic endocrine cells, whereas it was lacking in endocrine cells of the other tracts of the small and large bowel.

The expression of FGFR4 in the gut was restricted to some rectal $\mathrm{L}$ cells producing glicentin/PYY. In islet cells, FGFR4 was localized in A, B, and PP cells, whereas D cells did not express FGFR4.

In general, the pattern of immunoreactivity of various FGFRs was intense, finely granular, and cytoplasmic, 
TABLE 1. Summary of clinicopathologic data and immunohistochemical stainings of the 60 endocrine tumors investigated

\begin{tabular}{|c|c|c|c|c|c|c|c|c|c|c|c|c|c|}
\hline No. & Sex & Age & Site & Cell type & Class & $\begin{array}{l}\text { Fibrous } \\
\text { stroma }^{*}\end{array}$ & $\begin{array}{l}\text { Muscular } \\
\text { stroma* }^{*}\end{array}$ & $\begin{array}{c}\text { Metastases } \\
\text { or } \\
\text { invasion }\end{array}$ & aFGF & FGFR1 & FGFR2 & FGFR3 & FGFR4 \\
\hline 1 & $F$ & 65 & stomach & ECL cell, type 1 & WDET-B & NE & NE & no & 0 & 100 & 80 & 90 & NE \\
\hline 2 & $\mathrm{~F}$ & 90 & stomach & ECL cell, type 1 & WDET-B & NE & NE & no & 0 & 100 & 90 & 60 & 0 \\
\hline 3 & M & 76 & stomach & ECL cell, type 1 & WDET-U & $2+$ & $2+$ & no & 0 & 0 & 30 & 60 & 0 \\
\hline 4 & $\mathrm{M}$ & 43 & stomach & ECL cell, type 3 & WDEC & $1+$ & $2+$ & node & 0 & 0 & 10 & 5 & 0 \\
\hline 5 & $\mathrm{M}$ & 26 & stomach & ECL cell, type 3 & WDEC & $1+$ & $2+$ & node/liver & 0 & 40 & 0 & 10 & 0 \\
\hline 6 & $\mathrm{~F}$ & 56 & stomach & ECL cell, type 3 & WDEC & $1+$ & $1+$ & node & 0 & 0 & 0 & 90 & 40 \\
\hline 7 & $\mathrm{M}$ & 68 & stomach & undefined & PDEC & $1+$ & $2+$ & node/liver & 0 & 0 & 0 & 0 & 0 \\
\hline 8 & $M$ & 52 & stomach & undefined & PDEC & $1+$ & $1+$ & node & 0 & 0 & 0 & 90 & 0 \\
\hline 9 & $\mathrm{~F}$ & 52 & duodenum & $\mathrm{D}$ cell & WDEC & $1+$ & $1+$ & node & 0 & 60 & 0 & 70 & 0 \\
\hline 10 & $\mathrm{~F}$ & 38 & duodenum & D cell & WDEC & $1+$ & $1+$ & node & 0 & 20 & 2 & 20 & 50 \\
\hline 11 & $F$ & 46 & duodenum & $\mathrm{D}$ cell & WDEC & $1+$ & $1+$ & node/liver & 0 & 100 & 0 & 90 & 0 \\
\hline 12 & M & 52 & duodenum & D cell & WDEC & $1+$ & $1+$ & node & 0 & 0 & 0 & 0 & 0 \\
\hline 13 & $F$ & 42 & duodenum & $\mathrm{G}$ cell & WDET-B & $2+$ & $1+$ & no & 0 & 100 & 0 & 100 & 0 \\
\hline 14 & $F$ & 55 & duodenum & G cell & WDET-B & $1+$ & $1+$ & no & 0 & 20 & 0 & 80 & 0 \\
\hline 15 & M & 49 & duodenum & undefined & PDEC & $1+$ & $1+$ & node & 0 & 60 & 0 & 0 & 10 \\
\hline 16 & $\mathrm{~F}$ & 38 & jejunum & undefined & WDEC & $1+$ & $1+$ & node/liver & 0 & 80 & 5 & 70 & 90 \\
\hline 17 & $F$ & 67 & ileum & EC cell & WDEC & $2+$ & $2+$ & node/liver & 5 & 90 & 90 & 0 & 100 \\
\hline 18 & $\mathrm{M}$ & 52 & ileum & EC cell & WDEC & $3+$ & $2+$ & node/liver & 80 & NE & NE & 90 & 100 \\
\hline 19 & $\mathrm{M}$ & NE & ileum & EC cell & WDEC & $2+$ & $2+$ & no & 60 & 60 & 30 & 60 & 70 \\
\hline 20 & $F$ & 46 & ileum & EC cell & WDEC & $2+$ & $2+$ & node & 70 & 90 & 0 & 100 & 40 \\
\hline 21 & $M$ & 59 & ileum & EC cell & WDEC & $2+$ & $1+$ & NE & 70 & 20 & NE & 100 & 70 \\
\hline 22 & $\mathrm{M}$ & 58 & ileum & EC cell & WDEC & $2+$ & $2+$ & node/liver & 70 & 80 & 90 & 5 & 30 \\
\hline 23 & $M$ & 39 & ileum & EC cell & WDEC & $3+$ & $2+$ & node & 5 & 40 & 40 & 70 & 80 \\
\hline 24 & $\mathrm{~F}$ & 75 & ileum & EC cell & WDEC & $3+$ & $1+$ & liver & 80 & 40 & 70 & 70 & 70 \\
\hline 25 & $\mathrm{~F}$ & 69 & ileum & EC cell & WDEC & $2+$ & $1+$ & node & 40 & 80 & NE & 80 & 60 \\
\hline 26 & $M$ & 72 & ileum & EC cell & WDEC & $3+$ & $2+$ & omentum & 40 & 0 & 60 & 70 & 5 \\
\hline 27 & $\mathrm{M}$ & 53 & appendix & EC cell & WDET-B & $3+$ & $1+$ & no & 30 & 90 & 90 & 100 & 20 \\
\hline 28 & $M$ & 25 & appendix & EC cell & WDET-B & $2+$ & $1+$ & no & 10 & 60 & 2 & 80 & 60 \\
\hline 29 & $\mathrm{~F}$ & 95 & appendix & EC cell & WDET-B & $2+$ & $1+$ & no & 40 & 80 & 20 & 90 & 30 \\
\hline 30 & $\mathrm{~F}$ & 14 & appendix & EC cell & WDET-B & $3+$ & $1+$ & no & 70 & 90 & 5 & 100 & 20 \\
\hline 31 & $F$ & 17 & appendix & EC cell & WDET-B & $2+$ & $1+$ & no & 60 & 20 & 90 & 70 & 0 \\
\hline 32 & $\mathrm{~F}$ & 24 & appendix & EC cell & WDET-B & $3+$ & $1+$ & no & 60 & 90 & 90 & 90 & 0 \\
\hline 33 & $M$ & 27 & appendix & EC cell & WDET-B & $3+$ & $1+$ & no & 80 & 80 & NE & 100 & 60 \\
\hline 34 & $M$ & 27 & appendix & EC cell & WDET-B & $3+$ & $2+$ & no & 60 & 40 & 90 & 90 & 0 \\
\hline 35 & $F$ & 42 & appendix & EC cell & WDET-B & $2+$ & $2+$ & no & 30 & 90 & 90 & 100 & 30 \\
\hline 36 & $\mathrm{~F}$ & 24 & appendix & $\mathrm{L}$ cell & WDET-B & $3+$ & $1+$ & no & 0 & 100 & 80 & 90 & 90 \\
\hline 37 & NE & NE & right colon & EC cell & WDEC & $3+$ & $2+$ & ne & 5 & 30 & 90 & 70 & 80 \\
\hline 38 & $\mathrm{~F}$ & 50 & right colon & EC cell & WDEC & $2+$ & $2+$ & omentum & 5 & 40 & 40 & 100 & 70 \\
\hline 39 & $M$ & 46 & right colon & EC cell & WDEC & $2+$ & $1+$ & liver & 5 & 90 & 60 & 10 & 90 \\
\hline 40 & $F$ & 63 & right colon & undefined & PDEC & $1+$ & $1+$ & node & 0 & 0 & 0 & 60 & 10 \\
\hline 41 & $\mathrm{~F}$ & 51 & rectum & L cell & WDET-B & $1+$ & $1+$ & no & 0 & NE & 5 & 100 & 40 \\
\hline 42 & $\mathrm{~F}$ & 66 & rectum & L cell & WDET-B & ne & $1+$ & no & 0 & 80 & NE & 80 & 70 \\
\hline 43 & $M$ & 39 & rectum & $\mathrm{L}$ cell & WDET-B & $3+$ & $1+$ & no & 0 & 30 & 80 & 10 & 30 \\
\hline 44 & $\mathrm{M}$ & 54 & rectum & EC cell & WDET-B & $2+$ & $1+$ & no & 30 & 90 & 80 & 90 & 5 \\
\hline 45 & $\mathrm{M}$ & 66 & rectum & L cell & WDET-B & $1+$ & $1+$ & no & 0 & 50 & 5 & 100 & 80 \\
\hline 46 & $M$ & 70 & rectum & EC cell & WDEC & $3+$ & $2+$ & liver & 10 & 80 & 50 & 70 & 10 \\
\hline 47 & $\mathrm{~F}$ & 33 & pancreas & A cell & WDET-B & $1+$ & $1+$ & no & 0 & 80 & 20 & 80 & 80 \\
\hline 48 & $\mathrm{~F}$ & 63 & pancreas & A cell & WDET-B & $1+$ & $1+$ & no & 0 & 100 & 0 & 60 & 10 \\
\hline 49 & $\mathrm{M}$ & 66 & pancreas & A cell & WDET-B & $1+$ & $2+$ & no & 0 & 60 & 60 & 30 & 90 \\
\hline 50 & $\mathrm{M}$ & 62 & pancreas & undefined & WDET-U & $1+$ & $2+$ & no & 0 & 90 & 0 & 60 & 90 \\
\hline 51 & $F$ & 60 & pancreas & A cell & WDET-B & $1+$ & $1+$ & no & 0 & 90 & 70 & 70 & 30 \\
\hline 52 & $M$ & 62 & pancreas & EC cell & WDET-U & $2+$ & $2+$ & no & 5 & 0 & 0 & 40 & 2 \\
\hline 53 & $F$ & 75 & pancreas & EC cell & WDET-U & $2+$ & $2+$ & no & 0 & 2 & NE & 0 & 40 \\
\hline 54 & $\mathrm{M}$ & 70 & pancreas & undefined & WDET-U & $1+$ & $1+$ & no & 0 & 0 & 0 & 0 & 0 \\
\hline 55 & $\mathrm{M}$ & 67 & pancreas & Somatostatinoma & WDEC & $1+$ & $1+$ & no & 0 & 80 & NE & 0 & 20 \\
\hline 56 & $\mathrm{~F}$ & 54 & pancreas & Insulinoma & WDET-B & $1+$ & $1+$ & no & 0 & 0 & 80 & 60 & 90 \\
\hline 57 & $\mathrm{~F}$ & 50 & pancreas & Insulinoma & WDET-B & $1+$ & $2+$ & no & 0 & 80 & 3 & 90 & 80 \\
\hline 58 & $F$ & 40 & pancreas & Gastrinoma & WDEC & $2+$ & $2+$ & liver/node & 10 & 20 & 90 & 30 & 80 \\
\hline 59 & $M$ & 72 & pancreas & VIPoma & WDET-U & $1+$ & $1+$ & no & 0 & . 30 & 0 & 20 & 30 \\
\hline 60 & $\mathrm{~F}$ & 55 & pancreas & VIPoma & WDEC & $1+$ & $1+$ & liver & 0 & 100 & 100 & 70 & 80 \\
\hline
\end{tabular}

Class, tumor classification according to the World Health Organization classification (49,50); WDET-B, well-differentiated endocrine tumor with benign behavior; WDET-U, well-differentiated endocrine tumor with uncertain behavior; WDEC, well-differentiated endocrine carcinoma; PDEC, poorly differentiated endocrine carcinoma; NE, not evaluated; type 1, ECL cell carcinoid associated with chronic atrophic gastritis; type 3, sporadic ECL cell carcinoid.

* See Materials and Methods for explanation of scoring. 
TABLE 2. Functional endocrine cell types of adult human gut and pancreas

\begin{tabular}{|c|c|c|c|c|c|c|c|c|c|c|}
\hline \multirow[b]{2}{*}{ Cell type } & \multirow{2}{*}{$\begin{array}{l}\text { Hormone } \\
\text { or amine }\end{array}$} & \multirow[b]{2}{*}{ Pancreas } & \multicolumn{2}{|c|}{ Stomach } & \multicolumn{3}{|c|}{ Small bowel } & \multirow[b]{2}{*}{ Appendix } & \multicolumn{2}{|c|}{ Large bowel } \\
\hline & & & Fundus & Antrum & Duodenum & Jejunum & lleum & & Colon & Rectum \\
\hline ECL & Histamine & & + & & & & & & & \\
\hline $\mathrm{G}$ & Gastrin & & & + & + & & & & & \\
\hline $\mathrm{D}$ & Somatostatin & + & + & + & + & rare & rare & + & rare & + \\
\hline$A$ & Glucagon & + & & & & & & & & \\
\hline B & Insulin & + & & & & & & & & \\
\hline PP & PP & + & & & & & & & & \\
\hline $\mathrm{S}$ & Secretin & & & & + & + & & & & \\
\hline$M$ & Motilin & & & & + & + & & & & \\
\hline CCK & CCK & & & & + & + & & & & \\
\hline GIP & GIP & & & & + & + & & & & \\
\hline$E C$ & Serotonin & rare & + & + & + & + & + & + & + & + \\
\hline$N$ & Neurotensin & & & & & & + & & & \\
\hline L & GLI and PYY & & & & & & + & + & + & + \\
\hline
\end{tabular}

PP, pancreatic polypeptide; CCK, cholecystochinin; GIP, gastric inhibitory peptide; GLI, glucagon-like peptides; PYY, peptide tyrosinetyrosine.

with reinforcement at the cell membrane in some cells. In some cells, FGFR3 positivity also was present in the nucleus.

In addition to endocrine cells, all FGFRs were widely expressed in epithelial, endothelial, mesothelial, and muscular cells and fibroblasts of the tissues investigated.

\section{Endocrine Tumors}

The 60 endocrine tumors investigated included 6 gastric ECL cell carcinoids, 1 jejunal ET of undefined cell type, $4 \mathrm{D}$ cell and $2 \mathrm{G}$ cell tumors of the duodenum, 24 EC cell carcinoids of the small and large bowel, $5 \mathrm{~L}$ cell tumors of the rectum and appendix, 4 poorly differentiated endocrine carcinomas (PDECs), and 14 pancreatic ETs ( 2 insulinomas, 1 gastrinoma, 2 VIPomas, 9 nonfunctioning tumors of different cell type). The average age of patients was 52.8 years, ranging from 14 years to 95 years. Thirty-one patients were female and 28 were male; for 1 patient, gender information was not available.
Cytoplasmic immunoreactivity for aFGF was found in 26/60 (43\%) tumors (Table 5); 25 were EC cell carcinoids (Fig. 3) and 1 was a pancreatic gastrinoma with an EC cell component (case 58). The other types of ETs including ECL cell, D cell, G cell, and L cell neoplasms, PDECs, insulinomas, and VIPomas were aFGF-negative.

FGFRs were widely expressed among various types of ETs (Table 5), independent of FGFR expression in the putative cell of origin. FGFR1 was found in 47/58 (81\%) cases, FGFR2 in 36/53 (68\%), FGFR3 in 53/60 (88\%), and FGFR4 in 44/59 (74\%). All EC cell (Fig. 4) and all L cell ETs expressed at least three FGFRs, whereas gastric ECL cell tumors expressed at least two FGFRs (mainly FGFR2 and FGFR3), with FGFR4 being expressed in only one of the three type 3 carcinoids. Poorly differentiated endocrine carcinomas showed a low level of FGFR immunoreactivity, both in terms of the number of positive tumors and in terms of the number of immunoreactive cells per tumor. FGFR immunoreactivity was

TABLE 3. Antibodies and antisera used

\begin{tabular}{lcll}
\hline \multicolumn{1}{c}{ Antibodies/antisera } & P/M (clone) & Dilution & \\
\hline Glicentin-glucagon (Glic) & $\mathrm{P}$ & $1: 2500$ & Source \\
Glucagon (Gluc) & $\mathrm{P}$ & $1: 1250$ & Milab, Malmo, Sweden \\
Pancreatic polypeptide (PP) & $\mathrm{P}$ & $1: 4000$ & Cambridge Research Biochemicals, Cambridge, U.K. \\
Somatostatin (Som) & $\mathrm{P}$ & $1: 500$ & Dako, Copenhagen, Denmark \\
Somatostatin (Som) & M(YC7) & $1: 10$ & Immunochimica Labometrics, Milan, Italy \\
Secretin (Secr) & $\mathrm{P}$ & $1: 500$ & Milab \\
Serotonin (5HT) & M(YC5) & $1: 50$ & Biogenesis, Bournemouth, U.K. \\
Peptide YY (PYY) & $\mathrm{P}$ & $1: 1000$ & Biogenesis \\
Substance P (Sub P) & $\mathrm{P}$ & $1: 640$ & Milab \\
C-terminus gastrin-CCK-cerulein (Cer) & M(B4) & $1: 10000$ & Farmitalia, Milan, Italy \\
Gastrin 34 (Gastr) & $\mathrm{P}$ & $1: 500$ & Cambridge \\
$\alpha$-Smooth muscle specific actin & M(1A4) & $1: 10000$ & Sigma Immunochemicals, St. Louis, MO \\
Acidic fibroblast growth factor (aFGF) & $\mathrm{P}$ & $1: 100$ & UBI, Lake Placid, NY \\
Fibroblast growth factor receptor 1 (FGFR1) & $\mathrm{P}$ & $1: 100$ & Santa Cruz Biotechnology, Santa Cruz, CA \\
Fibroblast growth factor receptor 2 (FGFR2) & $\mathrm{P}$ & $1: 500$ & Santa Cruz Biotechnology \\
Fibroblast growth factor receptor 3 (FGFR3) & $\mathrm{P}$ & $1: 100$ & Santa Cruz Biotechnology \\
Fibroblast growth factor receptor 4 (FGFR4) & $\mathrm{P}$ & $1: 100$ & Santa Cruz Biotechnology \\
\hline
\end{tabular}

$\mathrm{P} / \mathrm{M}$, polyclonal/monoclonal. 
TABLE 4. Distribution of aFGF and FGFR immunoreactivity in normal endocrine cells of the gut and pancreas

\begin{tabular}{|c|c|c|c|c|c|c|c|c|c|}
\hline & \multicolumn{2}{|c|}{ Stomach } & \multicolumn{3}{|c|}{ Small bowel } & \multirow[b]{2}{*}{ Appendix } & \multicolumn{2}{|c|}{ Large bowel } & \multirow[b]{2}{*}{ Pancreas } \\
\hline & Fundus & Antrum & Duodenum & Jejunum & Ileum & & Right colon & Rectum & \\
\hline aFGF & rare & rare & $E C$ & $E C$ & $E C$ & $E C$ & $E C$ & $E C$ & - \\
\hline FGFR1 & - & - & rare & - & - & - & - & - & A \\
\hline FGFR2 & - & G & $\mathrm{G}$ & - & - & - & - & EC & B \\
\hline FGFR3 & - & G & G & - & - & - & - & - & rare \\
\hline FGFR4 & - & - & - & - & - & - & - & L & $A, B, P P$ \\
\hline
\end{tabular}

aFGF, acidic fibroblast growth factor; FGFR, fibroblast growth factor receptor.

cytoplasmic and diffuse, with membrane reinforcement in some cells, with the exception of nuclear FGFR3 immunoreactivity in a few cases. In addition to tumor cells, endothelial, mesothelial, and tumor stroma cells, including fibroblasts and smooth muscle cells, also expressed FGFRs.

The relation between the amount of tumor stroma, either fibrous or muscular, and the aFGF expression is summarized in Table 6. Tumors expressing aFGF (practically all EC cell carcinoids) presented an abundant tumor stroma with a significant fibrous and muscular component. The fibrous stroma of EC cell carcinoids (mean score $2.5+)$ was significantly $(P=0.01)$ more abundant than that of non-EC cell tumors (mean score $1.2+)$. The total stroma, which includes both the fibrous and muscular component, also was significantly $(P=$

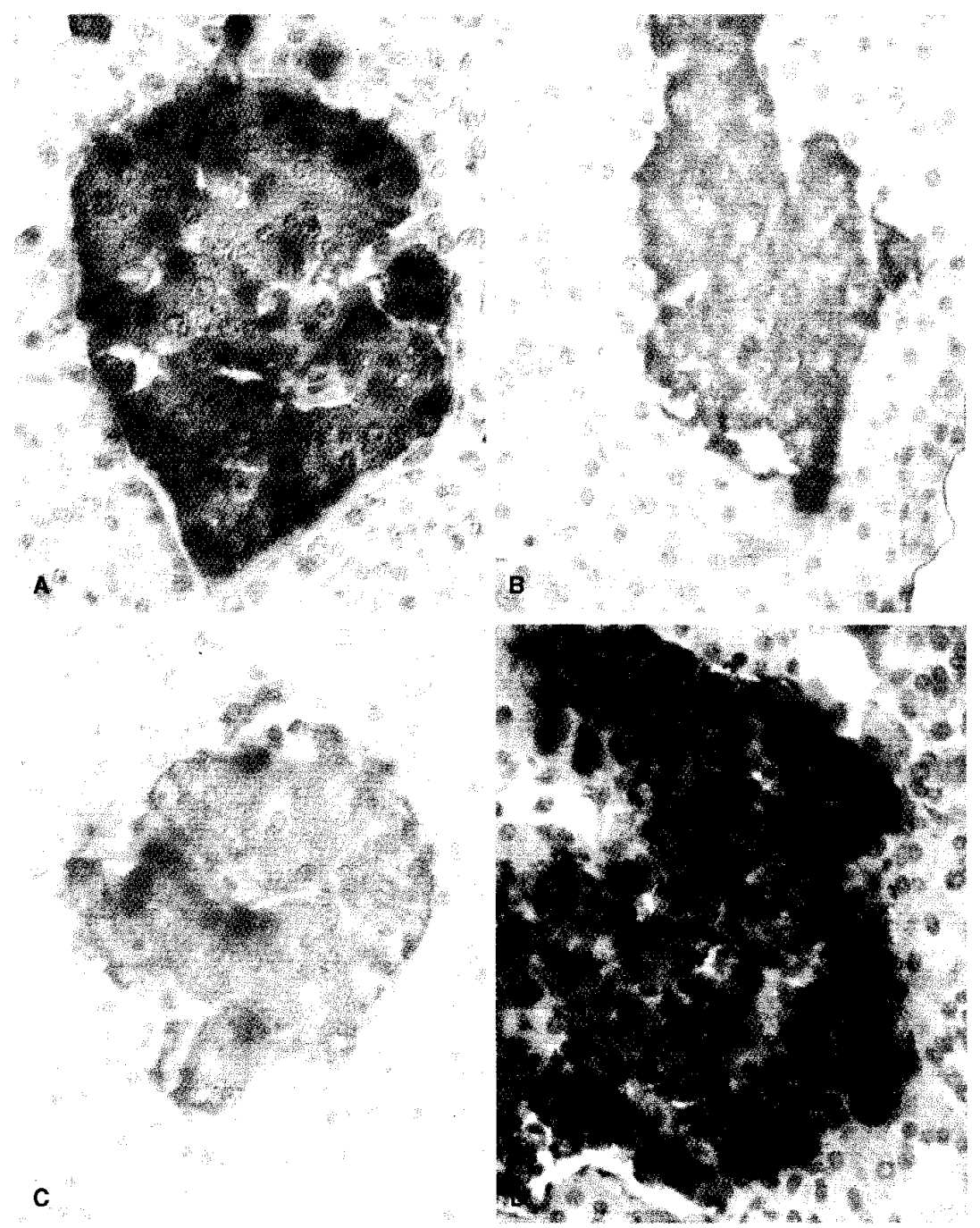

FIG. 1. Double-label immunostainings showing that FGFR2 (brown) is not expressed by glucagon immunoreactive (IR) A cells (A), pancreatic polypeptide IR PP cells (B), and somatostatin IR D cells (C), whereas it is colocalized with insulin in B cells (D). All hormones are stained in red. Avidin-biotin-peroxidase method for brown stain and alkaline phosphatase method for red stain. 

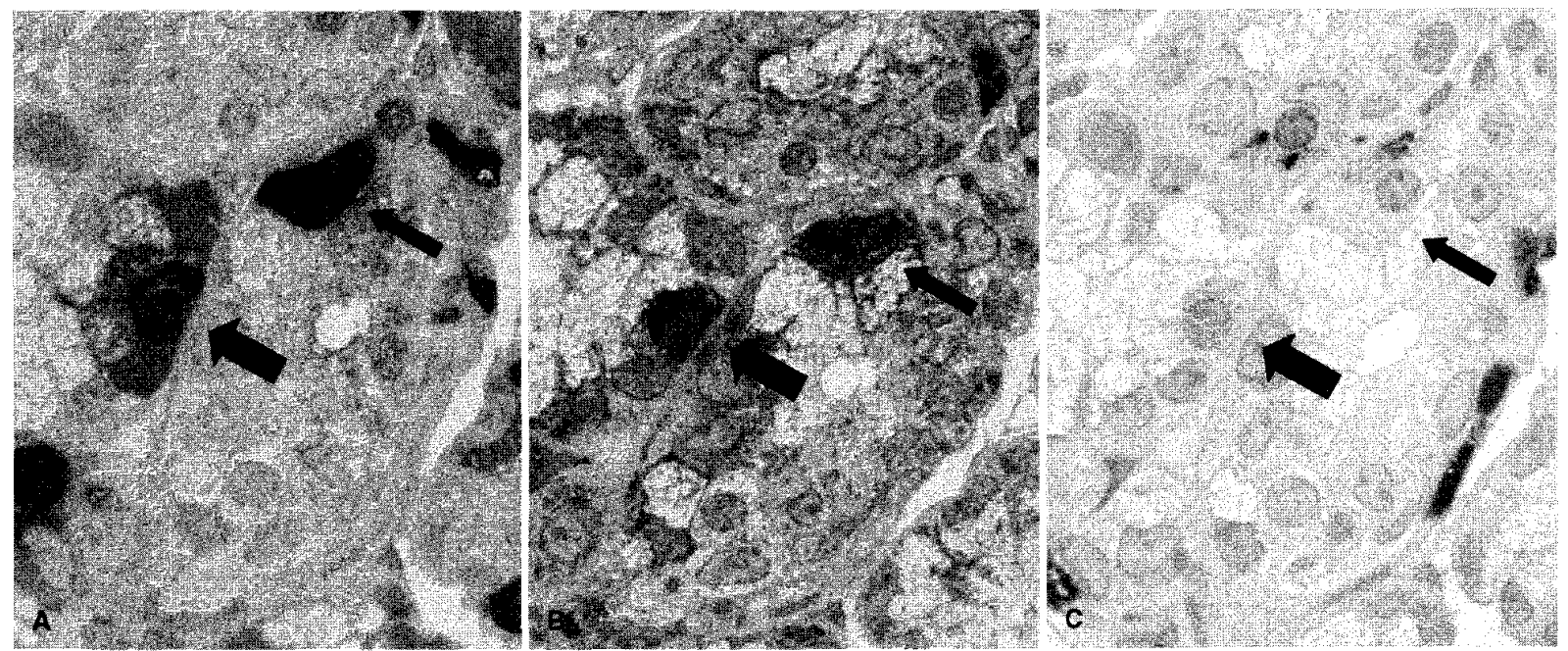

FIG. 2. Semithin serial sections of antral mucosa showing that gastrin immunoreactive (IR) cells (A) also are immunoreactive for FGFR3 (B), which is not expressed by serotonin IR cells (C) (arrows). Avidin-biotin-peroxidase method.

0.01 ) more abundant in EC cell carcinoids than in nonEC cell tumors.

\section{DISCUSSION}

The expression of various FGFRs in normal endocrine cells of the GEP system has been poorly investigated. FGFR4 was found to be expressed by normal rectal glicentin/PYY-producing L cells (15). To the best of the authors' knowledge, no studies of the distribution of FGFR1, FGFR2, and FGFR3 have been reported. In the current study, for the first time it is demonstrated that there is a specific distribution of various FGFRs among

TABLE 5. Distribution of aFGF and FGFR immunoreactivity in endocrine tumors of the gut and pancreas

\begin{tabular}{lccccc}
\hline \multicolumn{1}{c}{ Tumor type } & aFGF & FGFR1 & FGFR2 & FGFR3 & FGFR4 \\
\hline ECL cell & $0 / 6$ & $3 / 6$ & $4 / 6$ & $6 / 6$ & $1 / 5$ \\
D dell & $0 / 4$ & $3 / 4$ & $1 / 4$ & $3 / 4$ & $1 / 4$ \\
G cell & $0 / 2$ & $2 / 2$ & $0 / 2$ & $2 / 2$ & $0 / 2$ \\
Undefined cell & $0 / 1$ & $1 / 1$ & $1 / 1$ & $1 / 1$ & $1 / 1$ \\
EC cell (ileal) & $10 / 10$ & $8 / 9$ & $6 / 7$ & $9 / 10$ & $10 / 10$ \\
EC cell & & & & & \\
$\quad$ (appendiceal) & $9 / 9$ & $9 / 9$ & $8 / 8$ & $9 / 9$ & $6 / 9$ \\
EC cell & & & & & \\
$\quad$ (colorectal) & $5 / 5$ & $5 / 5$ & $5 / 5$ & $5 / 5$ & $5 / 5$ \\
cell & $0 / 5$ & $4 / 4$ & $4 / 4$ & $5 / 5$ & $5 / 5$ \\
PDEC & $0 / 4$ & $1 / 4$ & $0 / 4$ & $2 / 4$ & $2 / 4$ \\
Pancreas & $2 / 14^{*}$ & $11 / 14$ & $7 / 12$ & $11 / 14$ & $13 / 14$ \\
\hline Total & $26 / 60$ & $47 / 58$ & $36 / 53$ & $53 / 60$ & $44 / 59$ \\
& $(43 \%)$ & $(81 \%)$ & $(68 \%)$ & $(88 \%)$ & $(74 \%)$ \\
\hline
\end{tabular}

aFGF, acidic fibroblast growth factor; FGFR, fibroblast growth factor receptor, PDEC, poorly differentiated endocrine carcinomas.

* Of two aFGF-positive tumors, one was an EC cell tumor (case 52), and one was a gastrinoma with an EC cell component (case 58). gut and pancreatic endocrine cell types. Interestingly, although normal gastrointestinal EC cells express aFGF (current study and 14) and bFGF (13), they do not express FGFRs, with the exception of a subpopulation of rectal EC cells expressing FGFR2. This finding suggests that, in normal mucosa, autocrine interaction between

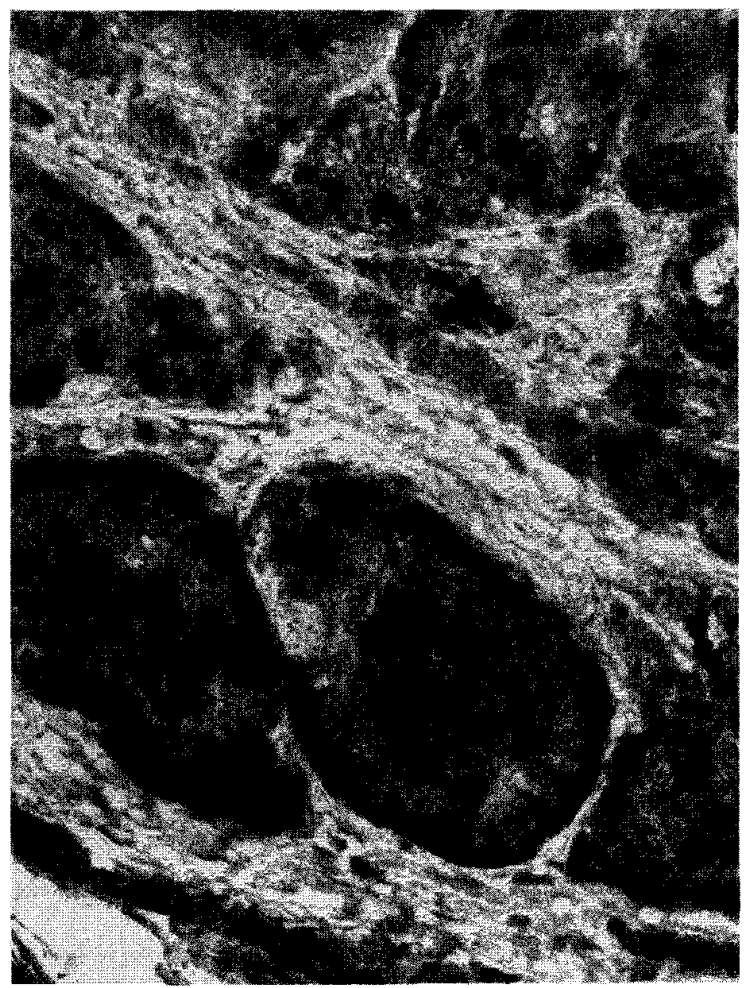

FIG. 3. Acidic fibroblast growth factor immunoreactivity in an EC cell tumor of the ileum. Avidin-biotin-peroxidase method. 

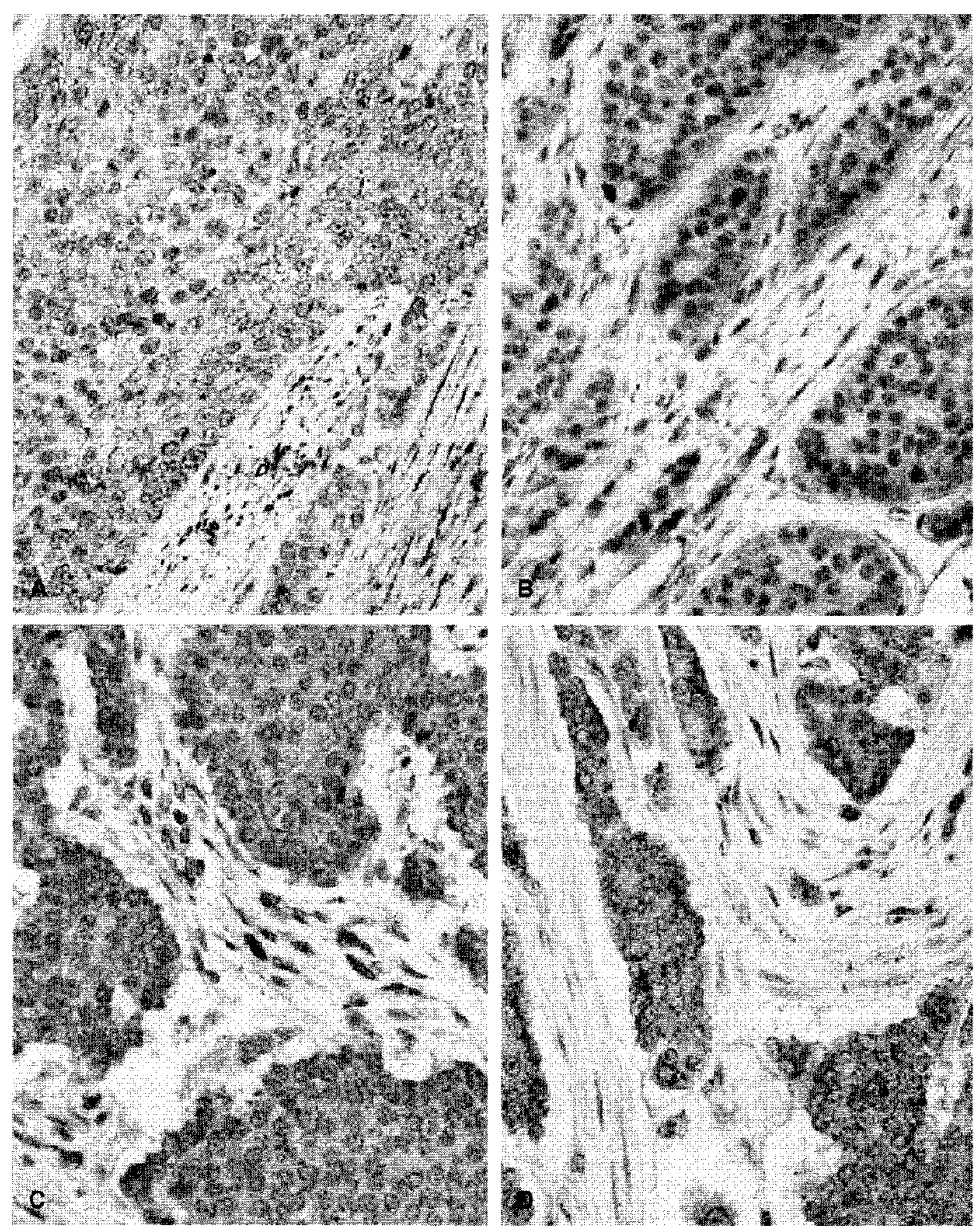

FIG. 4. Ileal EC cell tumors showing immunoreactivity for FGFR1 (A), FGFR2 (B), FGFR3 (C), and FGFR4 (D). In addition to neoplastic epithelial cells, stromal cells also are FGFRs immunoreactive. Avidinbiotin-peroxidase method.
aFGF and FGRFs or bFGF and FGFRs is probably not involved in modulating EC cell functions. However, aFGF-producing EC cells and bFGF-producing gastric $\mathrm{EC}$ and ECL cells may regulate, in a paracrine fashion, antroduodenal $\mathrm{G}$ cells, which according to the current results are FGFR2- and FGFR3-immunoreactive. Although this hypothesis is intriguing, further studies are needed to better clarify the functional role of FGFRs and their ligands in the modulation of the functional activity of normal gut endocrine cells. In addition, the current results prove that FGFRs are localized in superficial and glandular exocrine epithelial cells of gut mucosa, suggesting that, in normal conditions, endocrine cells, or at least EC and ECL cells, may influence exocrine epithelia through a paracrine mechanism involving aFGF, bFGF, and FGFRs. In this context, it is interesting to recall that, in the gut, aFGF and bFGF are known to be involved in mechanisms regulating mucosal repair and cell differentiation $(38-40)$.
Acidic FGF immunoreactivity was not found in pancreatic islet cells, agreeing with the study of Friess et al. (41), which shows that aFGF and bFGF are present in acinar and ductal cells of the pancreas, whereas they are absent in islet endocrine cells. In another report, bFGF was not detected in islet cells, confirming that this growth factor, like aFGF, is not expressed by the endocrine component of the pancreas (42). However, the authors clearly demonstrated strong immunoreactivities for FGFRs in islet cells. With the exception of FGFR3, FGFRs were well expressed and, in particular, FGFR I was localized in A cells, FGFR2 in B cells, and FGFR4 in A, B, and PP cells. The meaning of FGFR expression in pancreatic islet cells is unknown and it does not seem to be related to aFGF and bFGF production by the same cells. However, it is important to underline that these two growth factors belong to a large family comprising at least 20 structurally related proteins and it may be hypothesized that, in pancreatic islets, other members of 


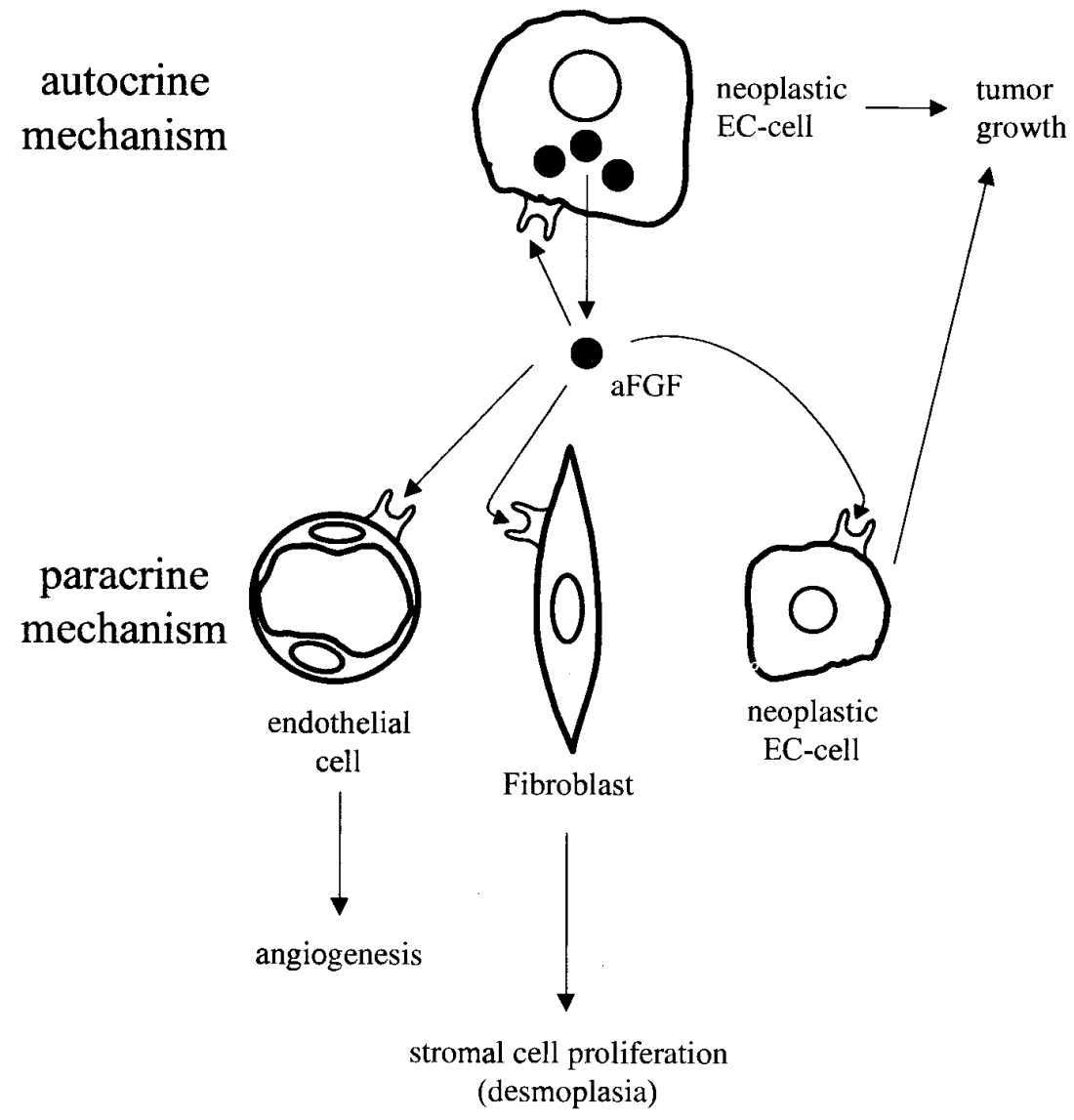

FIG. 5. Schematic representation of possible acidic fibroblast growth factor (aFGF) actions on EC cell tumors. EC cells produce aFGF, which is released with an unknown mechanism. aFGF may stimulate through paracrine mechanisms stromal and endothelial cells, which express FGFRs. The interaction between aFGF and FGFRs promotes tumor growth, stromal desmoplasia, and angiogenesis.

this family interact with FGFRs. Ishiwata et al. (43) recently have demonstrated that a few islet cells express keratinocyte growth factor, also known as FGF7, and its specific receptor (FGFR2). These results suggest that interaction between FGF7 and FGFR2 may be involved in the modulation of some functions of islet cells. In addition, because aFGF and bFGF are known to be expressed by exocrine cells of the pancreas $(41,42)$, it may be hypothesized that exocrine pancreatic cells regulate endocrine cell function through the interaction between aFGF/bFGF and the FGFRs expressed by islet cells.

Endocrine tumors of the GEP system show different clinicopathologic features depending on the cell type from which they derive $(34,44)$. In addition, GEP ETs, particularly gut ETs, show a wide spectrum of proliferation of host tissue including fibromuscular reaction of the gut wall, desmoplastic reaction of tumor stroma, fibrosis of peritoneal and retroperitoneal tissues, and fibroelastosis of mesenteric blood vessels (1-3). The tumorigenesis of ETs and the pathogenesis of these stromal lesions are not clear. Recent studies have provided evidence that GEP ETs produce several growth factors including insulin-like growth factor-I (IGF-I), transforming growth factor- $\alpha$ (TGF- $\alpha$ ) and $-\beta$ (TGF- $\beta$ ), activin A, platelet derived growth factor (PDGF), aFGF and bFGF, vascular endothelial growth factor (VEGF), and hepatocyte growth factor (HGF) $(4-17,45,46)$. Among these peptides, it has been suggested that aFGF and bFGF, which are well known as stimulators of fibroblast, smooth muscle, epithelial, and endothelial cell proliferation, are involved in the pathogenesis of fibromuscular proliferation within the tumor stroma $(14,15,18)$. Because the action of aFGF and bFGF depends on their interaction with specific cell receptors, it is of interest to know the exact localization of FGFRs. The expression of FGFRs in GEP ETs has been poorly investigated. In 1993, Chaudhry et al. (8) and Ahlman et al. (12) described an immunoreactivity for an unspecified FGFR in stromal vascular smooth muscle cells and fibroblasts

TABLE 6. Relation between aFGF expression and tumor stroma

\begin{tabular}{lccll}
\hline & \multicolumn{3}{c}{ Stroma $^{*}$} & \\
\cline { 2 - 4 } Tumor type & Fibrous & Muscular & Total & aFGF \\
\hline EC cell & $2.5+$ & $1.5+$ & $4+$ & $25 / 26+$ \\
Non-EC cell & $1.2+$ & $1.2+$ & $2.4+$ & $0 / 34$ \\
\hline
\end{tabular}

aFGF, acidic fibroblast growth factor.

* Mean values of data reported in Table 1.

† The aFGF negative EC cell tumor was pancreatic (case 53). 
of carcinoids showing positive staining for bFGF. In addition, Wulbrand et al. (16), using reverse transcription-polymerase chain reaction (RT-PCR), demonstrated the expression of FGFR mRNA in pancreatic gastrinomas, insulinomas, functioning intestinal EC-cell tumors, nonfunctioning gastric and intestinal endocrine tumors, but not in nonfunctioning pancreatic islet cell tumors. The type of FGFR investigated was not specified; however, checking the primer sequence used in the study at the National Library of Medicine with the BLAST basic local alignment search tool (http://www.ncbi.nlm.nih. gov/cgi-bin/BLAST/nph-newblast, accessed May 1998), the sequence used identified the Ig domains of FGFR1, FGFR2, and FGFR3 molecules. In the same study (16), it was not possible to discriminate whether the signal observed derived only from the stromal component or also from the epithelial component because of the methodologic procedure and technique used. In the current study, immunohistochemical techniques were used that, although known to be less sensitive than RT-PCR, provided the opportunity to identify the specific tumor cells expressing FGFRs. As shown in Table 5, various FGFRs were widely distributed among various endocrine tumors. ECL cell, EC cell, and L cell carcinoids represented the neoplasms in which FGFRs were more frequently expressed. The current results are comparable with those reported by Wulbrand et al. (16) who did not observe statistically significant differences in the FGFR mRNA expression among various types of ETs.

Comparing the FGFR distribution in normal endocrine cells and related tumors, it clearly appears that, with the exception of FGFR4 in rectal L cell tumors, all FGFRs are expressed de novo in the majority of ETs including ECL and EC cell carcinoids. In fact, normal ECL cells and the majority of EC cells, with the exception of few rectal EC cells expressing FGFR2, are not immunoreactive for FGFRs. The current results suggest that de novo expression of FGFRs may be involved in mechanisms of carcinoid tumorigenesis, at least for EC cell and ECL cell tumors. It is well known that de novo expression and overexpression are mechanisms involved in the oncogenetic potential of growth factors with tyrosine-kinase activity (47).

EC cell carcinoids, which produce aFGF and show immunoreactivity for at least three FGFRs, present a more abundant stroma than that of tumors negative for aFGF. This finding suggests that aFGF may be a factor inducing stromal proliferation through a paracrine mechanism. This hypothesis, which has been postulated in previous studies $(14,15)$, is now convincingly supported by the results presented in the current article demonstrating that stromal cells express FGFRs (Fig. 5).

In addition, a paracrine aFGF/FGFR binding may also be involved in vascular proliferation (angiogenesis) (48) in the stroma of EC cell tumors, which are generally well vascularized neoplasms, because endothelial cells express FGFRs.

FGFR immunoreactivity did not correlate with the Ki67 proliferative index (data not shown) and malignancy of the endocrine tumors investigated; indeed, in highly aggressive PDECs, FGFR immunoreactivity appeared to be low. These findings indicate that FGFRs are probably involved in tumor development but do not participate in the regulation of tumor progression, which may be regulated and modulated by other growth factors such as hepatocyte growth factor and scatter factor (46).

In conclusion, the current results demonstrate that aFGF and FGFRs are expressed by specific normal endocrine cell types of the gut and pancreas suggesting their possible role in the modulation of cell functions. In addition, aFGF is expressed by EC cell carcinoids whereas FGFRs are more widely expressed among various endocrine tumors of the digestive system. The interaction between aFGF and FGFRs may be involved, at least in EC cell carcinoids, in the modulation of tumor growth and tumor stroma proliferation.

\section{REFERENCES}

1. Horsley BL, Baker RR. Fibroblastic response to intestinal carcinoid. Am Surg 1970;36:676-80.

2. Qizilbash AH. Carcinoid tumors, vascular elastosis, and ischemic disease of the small intestine. Dis Colon Rectum 1977;20:554-60.

3. Bordi C, D’Adda T, Azzoni C, et al. Gastrointestinal endocrine tumors: recent developments. Endocr Pathol 1998;9:99-115.

4. Nilsson $O$, Wänberg B, Theodorsson $E$, et al. Presence of IGF-I in human midgut carcinoid tumours: an autocrine regulator of carcinoid tumour growth? Int J Cancer 1992;51:195-203.

5. Nilsson $\mathrm{O}$, Wänberg $\mathrm{B}, \mathrm{McRae} A$, et al. Growth factors and carcinoid tumours. Acta Oncol 1993;32:115-24.

6. Nilsson $\mathrm{O}$, Wänberg B, Kölby L, et al. Expression of transforming growth factor alpha and its receptor in human neuroendocrine tumours. Int J Cancer 1995;60:645-51.

7. Chaudhry A, Papanicolau V, Öberg K, et al. Expression of plateletderived growth factor and its receptors in neuroendocrine tumors of the digestive system. Cancer Res 1992;52:1006-12.

8. Chaudhry A, Funa K, Öberg K. Expression of growth factor peptides and their receptors in neuroendocrine tumors of the digestive system. Acta Oncol 1993;32:107-14.

9. Chaudhry A, Öberg K, Gobl A, et al. Expression of transforming growth factors $\beta_{1}, \beta_{2}, \beta_{3}$ in neuroendocrine tumors of the digestive system. Anticancer Res 1994;14:2085-91.

10. Beauchamp RD, Coffey RJ, Lyons RH, et al. Human carcinoid cell production of paracrine growth factors that can stimulate fibroblast and endothelial cell growth. Cancer Res 1991;51:5253-60.

11. Krishnamurthy S, Dayal Y. Immunohistochemical expression of transforming growth factor alpha and epidermal growth factor receptor in gastrointestinal carcinoids. Am J Surg Pathol 1997;21: 327-33.

12. Ahlman $\mathrm{H}$, Wänberg $B$, Nilsson $\mathrm{O}$. Growth regulation in carcinoid tumors. Endocrinol Metab Clin North Am 1993;22:889--915.

13. Bordi C, Falchetti A, Buffa R, et al. Production of basic fibroblast growth factor by gastric carcinoid tumors and their putative cell of origin. Hum Pathol 1994;25:175-80.

14. La Rosa S, Chiaravalli AM, Capella C, et al. Immunohistochemical localization of acidic fibroblast growth factor in normal human enterochromaffin cells and related gastrointestinal tumours. Virchows Arch 1997;430:117-24.

15. La Rosa S, Uccella S, Capella C, et al. Localization of acidic 
fibroblast growth factor, fibroblast growth factor receptor-4, transforming growth factor- $\alpha$, and epidermal growth factor receptor in human endocrine cells of the gut and related tumors: an immunohistochemical study. Appl Immunohistochem 1998;6:199-208.

16. Wulbrand U, Wied M, Zöfel P, et al. Growth factor receptor expression in human gastroenteropancreatic neuroendocrine tumours. Eur J Clin Invest 1998;28:1038-49.

17. Terris B, Scoazec JY, Rubbia L, et al. Expression of vascular endothelial growth factor in digestive neuroendocrine tumours. Histopathology I998;32:133-8.

18. Bordi C, Caruana P, D'Adda T, et al. Smooth muscle cell abnormalities associated with gastric ECL-cell carcinoids. Endocr Pathol 1995;6:103-13.

19. Klagsbrun $\mathbf{M}$. The fibroblast growth factor family: structural and biological properties. Prog Growth Factor Res 1989;1:207-35.

20. Tanaka A, Miyamoto K, Minamino N, et al. Cloning and characterization of an androgen-induced growth factor essential for the androgen-dependent growth of mouse mammary carcinoma cells. Proc Natl Acad Sci USA 1992;87:8928-32.

21. Miyamoto M, Narno K, Seko C, et al. Molecular cloning of a novel cytochine cDNA encoding the ninth member of the fibroblast growth factor family which has a unique secretory property. Mol Cell Biol 1993;13:4251-9.

22. Emoto H, Tagashira S, Mattei MG, et al. Structure and expression of human fibroblast growth factor-10. J Biol Chem 1997;272: 23191-4.

23. Verdier AS, Mattei MG, Lovec H, et al. Chromosomal mapping of two novel human FGF genes, FGF11 and FGF12. Genomics 1997; 40:151-4.

24. Hartung $\mathrm{H}$, Feldman B, Lovec $\mathrm{H}$, et al. Murine FGF-12 and FGF13: expression in embryonic nervous system, connective tissue and heart. Mech Dev 1997;64:31-9.

25. Smallwood PM, Munoz-Sanjuan I, Tong P, et al. Fibroblast growth factor (FGF) homologous factors: new members of the FGF family implicated in nervous system development. Proc Natl Acad Sci USA 1996;93:9850-7.

26. McWhirter JR, Goulding M, Weiner JA, et al. A novel fibroblast growth factor gene expressed in the developing nervous system is a downstream target of the chimeric homeodomain oncoprotein E2A-Pbx I. Development 1997;124:3221-32.

27. Miyake A, Konishi M, Martin FH, et al. Structure and expression of a novel member, FGF-16, of the fibroblast growth factor family. Biochem Biophys Res Commun 1998;243:148-52.

28. Hoshikawa M, Ohbayashi N, Yonamine A, et al. Structure and expression of a novel fibroblast growth factor, FGF-17, preferentially expressed in the embryonic brain. Biochem Biophys Res Commun 1998;244:187-91.

29. Maruoka Y, Ohbayashi N, Hoshikawa M, et al. Comparison of the expression of three highly related genes, Fgf8, Fgf 17 and Fgf 18 , in the mouse embryo. Mech Dev 1998;74:175-7.

30. Nishimura T, Utsunomiya $Y$, Hoshikawa $M$, et al. Structure and expression of a novel human FGF, FGF-19, expressed in the fetal brain. Biochim Biophys Acta 1999;1444:148-51.

31. Koga C, Adati N, Nakata $K$, et al. Characterization of a novel member of the FGF family, XFGF-20, in xenopus laevis. Biochem Biophys Res Commun 1999;261:756-65.

32. Galzie Z, Kinsella AR, Smith JA. Fibroblast growth factors and their receptors. Biochem Cell Biol 1997;75:669-85.
33. Johnson DE, Williams LT. Structural and functional diversity in the FGF receptor multigene family. Adv Cancer Res 1993;60:1-41.

34. Solcia E, Capella C, Fiocca R, et al. Disorders of the endocrine system. In: Ming SC, Goldman H, eds. Pathology of the gastrointestinal tract. Baltimore, MD: Williams \& Wilkins, 1998;295322.

35. Hsu SM, Raine L, Fanger $H$. Use of avidin-biotin-peroxidase complex (ABC) in immunoperoxidase technique. I Histochem Cytochem 1981;25:577-89.

36. Mason DY, Sammons R. Alkaline phosphatase and peroxidase for double immunoenzymatic labeling of cellular constituents. J Clin Pathol 1978;31:454-60.

37. Lan HY, Mu W, Nikolic-Paterson DJ, et al. A novel, simple, reliable, and sensitive methods for multiple immunoenzyme staining: use of microwave oven heating to block antibody crossreactivity and retrieve antigens. $J$ Histochem Cytochem 1995;43: 97-102.

38. Fitzpatrick LR, Jakubowska A, Martin GE, et al. Acidic fibroblast growth factor accelerates the healing of acetic-acid-induced gastric ulcers in rats. Digestion 1992;53:17-27.

39. Hull MA, Cullen DJE, Hudson N, et al. Basic fibroblast growth factor treatment for non-steroidal anti-inflammatory drug associated gastric ulceration. Gut 1995;37:610-12.

40. Szabo S, Kusstatscher S, Sakoulas G, et al. Growth factors: new 'endogenous drugs' for ulcer healing. Scand J Gastroenterol Suppl $1995 ; 210: 15-8$.

41. Friess H, Yamanaka Y, Büchler M, et al. Increased expression of acidic and basic fibroblast growth factors in chronic pancreatitis. Am J Pathol 1994;144:117-28.

42. Yamazaki K, Nagao T, Yamaguchi T, et al. Expression of basic fibroblast growth factor (FGF-2)-associated with tumour proliferation in human pancreatic carcinoma. Virchows Arch 1997;431: 95-101.

43. Ishiwata T, Friess H, Büchler MW, et al. Characterization of keratinocyte growth factor and receptor expression in human pancreatic cancer. Am J Pathol 1998;153:213-22.

44. Solcia E, Capella C, Klöppel G. Tumors of the endocrine pancreas. In: J Rosai, ed. Tumors of the pancreas. Atlas of tumor pathology, $3^{\text {rd }}$ edition. Washington, DC: Armed Forces Institute of Pathology, 1997:145-209.

45. La Rosa S, Uccella S, Billo P, et al. Immunohistochemical localization of $\alpha$ - and $\beta A$-subunits of inhibin/activin in human normal endocrine cells and related tumors of the digestive system. Virchows Arch 1999;434:29-36.

46. La Rosa S, Uccella S, Capella C et al. Localization of hepatocyte growth factor and its receptor met in endocrine cells and related tumors of the gut and pancreas. An immunohistochemical study. Endocr Pathol (in press)

47. Yarden Y. Growth factor receptor tyrosine kinases. Ann Rev Biochem 1988;57:443-78.

48. Jugenburg M, Kovacs K, Jugenburg I, et al. Angiogenesis in endocrine neoplasms. Endorc Pathol 1998;8:259-72.

49. Solcia E, Klöppel G, Sobin LH, et al. Histologic typing of endocrine tumors. WHO international classification of tumors. Heidelberg: Springer-Verlag, 2000.

50. Hamilton SR, Aaltonen LA, eds. Pathology and genetic of tumors of the digestive system. WHO classification of tumors. Lyon, France: IARC Press, 2000. 